\title{
La biometría hemática
}

\section{Blood cytometry.}

López-Santiago N

La biometría hemática, o citometría hemática como también se le conoce, es el examen de laboratorio de mayor utilidad y más frecuentemente solicitado por el clínico. Esto es debido a que en un solo estudio se analizan tres líneas celulares completamente diferentes: eritroide, leucocitaria y plaquetaria, que no sólo orientan a patologías hematológicas; sino también a enfermedades de diferentes órganos y sistemas.

\section{Serie roja (eritroide)}

Se evalúa tanto por la cantidad de eritrocitos como por su contenido de hemoglobina. Es importante tomar en cuenta que estos parámetros varían de acuerdo con la altura sobre el nivel del mar, la edad y el género del paciente. Por otra parte, los índices eritrocitarios que indican el contenido de hemoglobina por eritrocito y el tamaño de cada uno de ellos, son datos importantes que orientan a las posibles etiologías en pacientes con anemia; estos valores se realizan en una forma muy exacta calculados en equipos automatizados.

La hemoglobina es la proteína contenida en el eritrocito; su principal función es el transporte de $\mathrm{O}_{2} / \mathrm{CO}_{2}$ de los pulmones a los tejidos y viceversa. En el adulto sano existen de 4.62 a $5.2 \times 10^{12} / \mathrm{L}$ de eritrocitos y representan aproximadamente $45 \%$ de del volumen sanguíneo circulante cuando se centrifuga la sangre; la proporción que estos guardan con el plasma se conoce como hematocrito. La hemoglobina y el hematocrito variarán de acuerdo con la edad de los niños (Cuadro 1).

Conocer el tamaño de cada eritrocito y su contenido de hemoglobina se logra con los índices eritrocitarios:
Servicio de Hematología, Instituto Nacional de Pediatría.

Recibido: 30 de noviembre del 2015

Aceptado: 9 de mayo del 2016

Correspondencia

Norma López Santiago

Servicio de Hematología

Instituto Nacional de Pediatría

Insurgentes sur \# 3700-C

CP 04530 Ciudad de México, México.

nolsa99@yahoo.com

Este artículo debe citarse como

López-Santiago N. La biometría hemática. Acta Pediatr Mex. 2016;37(4):246-249. 
Cuadro 1. Índices hematológicos de acuerdo con la edad

\begin{tabular}{|c|c|c|c|c|c|c|c|}
\hline Edad & $\begin{array}{c}\mathrm{Hb} \\
(\mathrm{g} / \mathrm{dL})\end{array}$ & $\begin{array}{l}\text { Hto } \\
(\%)\end{array}$ & $\begin{array}{l}\text { VCM } \\
\text { (FI) }\end{array}$ & $\begin{array}{l}\text { CHCM } \\
(\mathrm{g} / \%)\end{array}$ & Reticulocitos & $\begin{array}{l}\text { Leucocitos P } \\
\left(\mathbf{1 0}^{3} / \mathrm{mm}^{3}\right)\end{array}$ & $\begin{array}{l}\text { Plaquetas } \\
\left(10^{3} / \mathrm{mm}^{3}\right)\end{array}$ \\
\hline $\begin{array}{l}\text { 26-30sem de ges- } \\
\text { tación }\end{array}$ & 13.4 & 41.5 & 118.2 & 37.9 & - & 4.4 & 254 \\
\hline 32 sem & 15.0 & 47 & 118 & 32 & $3-10$ & - & 290 \\
\hline A término (CU) & $13.5-16.5$ & 51 & 108 & 33 & $3-7$ & 18.1 & 290 \\
\hline $1-3 d$ & $14.5-18.5$ & 56 & 108 & 33 & $1.8-4.6$ & 18.9 & 192 \\
\hline 2 sem & $13.4-16.6$ & 53 & 105 & 31.4 & & 11.4 & 252 \\
\hline $2 m$ & $10.7-11.2$ & 35 & 95 & 31.8 & $0.1-1.7$ & 10.8 & \\
\hline $6 m$ & $9.4-12.6$ & 36 & 76 & 35 & $0.7-2.3$ & 11.9 & \\
\hline $6 m-2 a$ & 11.1-10.5- & 36 & 78 & 33 & & 10.6 & $150-350$ \\
\hline $2-6 a$ & $10.5-12$ & 37 & 81 & 34.0 & $0.5-1$ & 8.5 & $150-350$ \\
\hline $6-12$ & $11.5-13.5$ & 40 & 86 & 34 & $0.5-1$ & 8.1 & $150-350$ \\
\hline \multicolumn{8}{|l|}{$12-18 a$} \\
\hline Hombre & $13-14.5$ & 43 & 88 & 34 & $0.5-1$ & 7.8 & $150-350$ \\
\hline Mujer & $12-14.0$ & 41 & 90 & 34 & $0.5-1$ & 7.8 & $150-350$ \\
\hline \multicolumn{8}{|l|}{ Adulto } \\
\hline Hombre & $13.5-15.5$ & 47 & 90 & 34 & $0.8-2.5$ & 7.4 & $150-350$ \\
\hline Mujer & $12-14.0$ & 41 & 90 & 34 & $0.8-4.1$ & 7.4 & $150-350$ \\
\hline
\end{tabular}

Hb: hemoglobina; Hto: hematocrito; VCM: volumen corpuscular medio; CHCM: concentración media de hemoglobina corpuscular. Modificado de Manual Harriet Lane de Pediatría, 16ª . Edición, 2003.

Volumen corpuscular medio. Indica el tamaño y capacidad del eritrocito, y se mide en fentolitros ( $f \mathrm{~L})$. De acuerdo con el tamaño permite clasificar como normocítica, microcítica o macrocítica.

Hemoglobina corpuscular media. Indica la cantidad de hemoglobina contenida en un eritrocito y se expresa en picogramos (pg).

Concentración media de hemoglobina corpuscular. Es el promedio de la concentración de hemoglobina en $100 \mathrm{~mL}$ de eritrocitos y se expresa en $\mathrm{g} / \mathrm{dL}$. Tanto la hemoglobina corpuscular media como la concentración media de hemoglobina corpuscular permiten clasificar a los eritrocitos como normocrómicos, hipocrómicos, o hipercrómicos, aunque estos últimos excepcionalmente serán informados.

La amplitud de distribución eritrocitaria. Representa el coeficiente de variación del volumen de los eritrocitos y es reportado en porcentaje.

Reticulocitos. Son eritrocitos jóvenes que contienen aún restos de retículo endoplásmico en su citoplasma. Son discretamente más grandes que los eritrocitos maduros en la tinción y sólo se pueden identificar en forma exacta con tinciones supravitales. De mayor utilidad es conocer el número de reticulocitos corregido en relación con el hematocrito de acuerdo con la siguiente fórmula: hematocrito real $x \%$ reticulocitos informados /hematocrito ideal.

La forma normal del eritrocito es la de un disco bicóncavo de aproximadamente 6 micras de diámetro; en algunas condiciones patológicas, como la deficiencia de hierro, los eritrocitos pueden ser muy pequeños (microcitosis) o de un tamaño considerablemente mayor, como en la anemia megaloblástica (macrocitosis) (Cuadro 2). Cuando estas variaciones son 
Cuadro 2. Clasificación de las anemias de acuerdo con índices eritrocitarios

\begin{tabular}{|c|c|}
\hline Microcítica hipocrómica & $\begin{array}{l}\text { Deficiencia de hierro } \\
\text { Talasemias } \\
\text { Intoxicación por plomo } \\
\text { Enfermedades crónicas }\end{array}$ \\
\hline Macrocítica & $\begin{array}{l}\text { Deficiencia de folatos/vita } \\
\text { mina B12 } \\
\text { Mielodisplasia } \\
\text { Enfermedad hepática } \\
\text { Quimioterapia } \\
\text { Reticulocitosis }\end{array}$ \\
\hline Normocítica & $\begin{array}{l}\text { Enfermedades crónicas } \\
\text { Mieloptisis } \\
\text { Síndromes mielo o linfopro- } \\
\text { liferativos }\end{array}$ \\
\hline
\end{tabular}

identificadas en el frotis de sangre periférica se denomina anisocitosis. Por otra parte, podemos identificar alteraciones en la forma: esquistocitos, drepanocitos, células bipolares, ovalocitos, etc., que son informados como poiquilocitosis, por lo que es importante que en un paciente con anemia, cuando se informa anisocitosis o poiquilocitosis, se debe realizar una revisión cuidadosa del frotis de sangre periférica que será de gran ayuda para orientar el diagnóstico etiológico.

\section{Serie leucocitaria}

Los leucocitos son las células nucleadas de la sangre; incluyen a los neutrófilos segmentados y en banda, monocitos, eosinófilos y basófilos que forman parte de la inmunidad innata de cada individuo. Los linfocitos corresponden a las células que participan en la inmunidad adaptativa. En el niño la distribución de los leucocitos varía con la edad, pero es importante recordar que más que el porcentaje en la biometría hemática, deben tomarse en cuenta los valores absolutos de cada uno de ellos; así, los neutrófilos absolutos en los primeros seis meses de vida deben ser superiores a $1,000 / \mathrm{mm}^{3}$, mientras que posterior a esta edad los deberemos encontrar por arriba de 1,500/ $\mathrm{mm}^{3}$. En cuanto a los linfocitos en la circulación encontraremos un mínimo de $1,000 / \mathrm{mm}^{3}$, que corresponden a linfocitos B y T, aunque morfológicamente es imposible distinguirlos (Cuadro 3).

Los procesos infecciosos locales o sistémicos son la causa principal de modificaciones en el número total y diferencial de leucocitos. La leucocitosis es la elevación de leucocitos totales en la circulación; una cuenta total por arriba de $30 \times 10^{3}$ se conoce como reacción leucemoide, en la que sólo se identifican formas maduras en la circulación. Cuando la leucocitosis es secundaria a infecciones bacterianas el predominio es de neutrófilo y puede haber un incremento de bandas; en cambio, ante la presencia de infecciones virales tiende a aparecer un marcado incremento de linfocitos. La mononucleosis infecciosa es el ejemplo típico de reacción leucemoide con incremento de linfocitos y aparición de linfocitos atípicos. En forma paradójica, algunas infecciones pueden asociarse a leucopenia; la bacteria más frecuentemente asociada con neutropenia es la causada por Salmonella. Las enfermedades hematológicas malignas son una causa frecuente de leucocitosis/leucopenia. En estos casos es necesaria una revisión cuidadosa del frotis de sangre periférica en donde se demostrará neutropenia y con frecuencia podemos encontrar células inmaduras, blastos, asociado a disminución de la hemoglobina y de las plaquetas. Deficiencias nutricionales, estrés, drogas, etc., son problemas médicos que pueden causar modificaciones en el número de neutrófilos (Cuadro 4).

\section{Serie plaquetaria}

La tercera línea celular evaluada en la biometría hemática es la de plaquetas. A diferencia de lo que sucede con eritrocitos y leucocitos, las plaquetas tienen un número constante a lo largo de la vida que varía entre 150-450 × 10\%/ , miden de 1-3 mm/L; los equipos automatizados utilizados en la actualidad proporcionan además el volumen plaquetario medio que va de 5-12 fentolitros ( $\mathrm{fL}$ ). Las plaquetas circulantes simulan 
Cuadro 3. Variaciones en la distribución de leucocitos de acuerdo con la edad $\left(\times 10^{3} / \mathrm{mm}^{3}\right)$

\begin{tabular}{|c|c|c|c|c|c|c|c|}
\hline Edad & $\begin{array}{l}\text { Leucocitos totales } \\
\text { Media } \times 10^{3} \\
\text { (intervalo) }\end{array}$ & $\begin{array}{l}\text { Neutrófilos } \\
\text { Media } \times 10^{3} \\
\text { (intervalo) }\end{array}$ & $\%$ & $\begin{array}{l}\text { Linfocitos } \\
\text { Media x10 } \\
\text { (intervalo) }\end{array}$ & $\%$ & $\begin{array}{l}\text { Monocitos } \\
\text { Media } \times 10^{3} \\
(\%)\end{array}$ & $\begin{array}{c}\text { Eosinófilos } \\
\text { Media } \times 10^{3} \\
(\%)\end{array}$ \\
\hline $\mathrm{RN}$ & $18.1(9-30)$ & $11(6-26)$ & 61 & $5.5(2-11)$ & 31 & $1.1(6)$ & $0.4(2)$ \\
\hline $12 \mathrm{~h}$ & $22.8(13-38)$ & $15.5(6-28)$ & 68 & $5.5(2-11)$ & 24 & $1.2(5)$ & $0.5(2)$ \\
\hline $24 \mathrm{~h}$ & $18.9(9.4-34)$ & $11.5(5-21)$ & 61 & $5.8(2-11.5)$ & 31 & $1.1(6)$ & $0.5(2)$ \\
\hline $1 \mathrm{~s}$ & $12.2(5-21)$ & $5.5(1.5-10)$ & 45 & $5.0(2-17)$ & 41 & $1.1(9)$ & $1.5(4)$ \\
\hline $1 \mathrm{~m}$ & $10.8(5-19.5)$ & $3.8(1-8.5)$ & 35 & $6.0(2.5-16.5)$ & 56 & $0.7(7)$ & $0.3(3)$ \\
\hline $6 m$ & $11.9(6-17.5)$ & $3.8(1-8.5)$ & 32 & $7.3(4-13.5)$ & 61 & $0.6(5)$ & $0.3(3)$ \\
\hline $1 \mathrm{a}$ & $11.4(6-17.5)$ & $3.5(1.5-8.5)$ & 31 & $7.0(4-10.5)$ & 61 & $0.6(5)$ & $0.3(3)$ \\
\hline $2 a$ & $10.6(6-17)$ & $3.5(1.5-8.5)$ & 33 & $6.3(3-9.5)$ & 59 & $0.5(5)$ & $0.3(3)$ \\
\hline $4 a$ & $9.1(5.5-15.5)$ & $3.8(1.5-8.5)$ & 42 & $4.5(2-8)$ & 50 & $0.5(5)$ & $0.3(3)$ \\
\hline $6 a$ & $8.5(5-14.5)$ & $4.3(1.5-8)$ & 51 & $3.5(1.5-7)$ & 42 & $0.4(5)$ & $0.2(3)$ \\
\hline $8 a$ & $8.3(4.5-13.5)$ & $4.4(1.5-8)$ & 53 & $3.3(1.5-6.8)$ & 39 & $0.4(4)$ & $0.2(2)$ \\
\hline $10 \mathrm{a}$ & $8.1(4.5-13.5)$ & $4.4(1.5-8.5)$ & 54 & $3.1(1.5-6.5)$ & 38 & $0.4(4)$ & $0.2(2)$ \\
\hline $16 a$ & $7.8(4.5-13)$ & $4.4(1.8-8)$ & 57 & $2.8(1.2-5.2)$ & 35 & $0.4(5)$ & $0.2(3)$ \\
\hline $21 a$ & $7.4(4.5-11.0)$ & $4.4(1.8-7.7)$ & 59 & $2.5(1-4.8)$ & 34 & $0.3(4)$ & $0.2(3)$ \\
\hline
\end{tabular}

RN: recién nacido; h: horas; s: semana; m: meses; a: años. Modificado de Manual Harriet Lane de Pediatría, 16 ${ }^{a}$. Edición, 2003.

Cuadro 4. Alteraciones cuantitativas de los neutrófilos

\begin{tabular}{|c|c|}
\hline Neutrofilia & Neutropenia \\
\hline $\begin{array}{l}\text { Infecciones/inflamación/ } \\
\text { daño tisular } \\
\text { Enfermedades mieloproli- } \\
\text { ferativas } \\
\text { Estrés: eclampsia, cetoaci- } \\
\text { dosis, etc. } \\
\text { Esteroides }\end{array}$ & $\begin{array}{l}\text { Recién nacidos: } \\
\text { Enfermedad isoinmune } \\
\text { Infección } \\
\text { Ingestión materna de drogas } \\
\text { Neutropenias congénitas } \\
\text { (síndrome Kostman, inmu- } \\
\text { nodeficiencias, etc.) }\end{array}$ \\
\hline Esplenectomía & $\begin{array}{l}\text { Niños mayores: } \\
\text { Infecciones } \\
\text { Drogas } \\
\text { Deficiencias de vitaminas } \\
\text { Neoplasia hematológica } \\
\text { Neutropenia cíclica }\end{array}$ \\
\hline
\end{tabular}

un disco oblongo; son fragmentos anucleados del citoplasma de los megacariocitos presentes en la médula ósea, que sólo contienen algunas mitocondrias, glucógeno y gránulos específicos importantes para la coagulación. Las alteraciones numéricas de las plaquetas se pueden evaluar considerando el volumen plaquetario medio: uno elevado traduce una proliferación acelerada en la médula ósea (anemias hemolíticas, aumento de destrucción en la circulación) mientras uno disminuido se asocia con reducción en la trombopoyesis.
Esta prueba se realiza en sangre fresca; se prefiere el ácido etilendiaminotetraacético debido a que no afecta la morfología de las células ni modifica la sedimentación globular. Aunque se puede utilizar citrato de sodio, éste se usa sólo cuando se sospecha pseudotrombocitopenia, o heparina que no evita la agregación plaquetaria en su totalidad además de que produce una tinción azulosa a las células cuando son teñidas con Wright.

\section{LECTURAS RECOMENDADAS}

1. Aquino J. Hematology. En Johns Hopkins: The Harriet Lane Hand book, 18th Ed. Mosby, 2008, pp. 289-313.

2. Kjeldsberg CR. Principios del examen hematológico. En Wintrobe Hematología Clínica 9ạ Ed., Editorial Lee GR, Bithell TC, Foerester J, Athens JW, Lukens JN. Inter-Médica Editorial, Buenos Aires Argentina 1994, pp. 6-31.

3. Trastornos cuantitativos y cualitativos de los neutrófilos. En Hematología en la práctica clínica 4a Ed. Hillman RS, Ault KA, Rinder HM. Mc Graw-Hill 2005, pp. 197-205.

4. Terol-Castera MJ, García Conde J. Exploración del enfermo hematológico. Clasificación de las enfermedades hematológicas. En Hematología, Editores J García Conde, JF San Miguel, J Sierra, A Urbano-IspizuaV, Vives-Corrons JL. Arán ediciones SL 2007, pp. 3-16.

5. Villarrubia-Espinoza J, Reverter Calatayud C. Automatización en hematología. En Hematología, Editores J García Conde, JF San Miguel, J Sierra, A Urbano-IspizuaV Vicente, JL Vives-Corrons. Arán ediciones SL 2007, pp. 17-25. 